\title{
Efeito de concentrações de espalhante adesionante e doses de glyphosate no controle de Brachiaria decumbens e Panicum maximum ${ }^{1}$
}

\author{
EDIVALDO D. VELINI ${ }^{2}$, DAGOBERTO MARTINS ${ }^{2}$ e MARCO A. DE SOUZA SILVA ${ }^{3}$
}

\begin{abstract}
Foram avaliadas as interações entre $\mathrm{O}$ glyphosate e o espalhante adesionante correspondente ao condensado de alcoolfenóis com óxido de eteno e sulfonados orgânicos quanto à redução de tensão superficial e ao controle de Panicum maximum e Brachiaria decumbens. Os produtos comerciais apresentavam $360 \mathrm{~g}$ e.a./l e 466 g i.a./l, respectivamente. $O$ herbicida reduziu
\end{abstract}

RESUMO o efeito do espalhante sobre a tensão superficial. $\mathrm{Na}$ concentração de $0,1 \%$ de p.c., o espalhante maximizou o controle das duas espécies pelo glyphosate. $P$. maximum mostrou-se menos sensível ao glyphosate que $B$. decumbens, exigindo doses $24,05 \%$ superiores.

Palavras chave: Glyphosate, surfatante, tensão superficial, controle.

\section{ABSTRACT \\ Effects of adhesive spreading and glyphosate on Brachiaria decumbens and Panicum maximum control}

The interactions of glyphosate and one adhesive spreading (concentrate of alcoholphenols with ethene-oxide and organic sulfonates) in reducing the surface tension and controlling Brachiaria decumbens and Panicum maximum were evaluated. It were used comercial products with $360 \mathrm{~g}$ a.e/l and $466 \mathrm{~g}$ i.a./l, respectivelly. To achieve similar control levels, the herbicide rates

\section{INTRODUÇÃO}

O glyphosate é hoje o herbicida de mais ampla utilização no Brasil. No entanto, são poucos os trabalhos realizados no Brasil procurando modificar e ajustar as condições de aplicação deste herbicida, incluindo o uso de surfactantes, procurando maximizar a sua eficiência. Mas, quando feitos, tais trabalhos têm indicado que mudanças nas condições de aplicação podem alterar a eficácia do glyphosate, modificando as doses necessárias do mesmo, sendo exemplos os trabalhos de Foloni (1995) e Silva (1996).

Também são escassos os trabalhos de revisão ou pesquisa sobre surfatantes disponíveis should be $24,05 \%$ higher for the second species. The herbicide reduced the effect of the surfactant on surface tension. The concentration of $0,1 \%$ (c.p.) of the surfactant maximized the efficacy of glyphosate in controlling the two grasses.

Key words: Glyphosate, surfactant, surface tension, efficacy.

no Brasil. Devem ser destacados os trabalhos de Matuo et al. (1989), Camargo \& Silva (1993), Durigan (1993), Velini et al. (1993), Mendonça et al. (1996) e Costa (1997).

Este trabalho teve por objetivo avaliar os efeitos de um espalhante adesivo com características aniônicas e não iônicas sobre a eficiência do glyphosate no controle de Brachiaria decumbens Stapf e Panicum maximum Jacq.

\section{MATERIAL E MÉTODOS}

O presente trabalho foi desenvolvido em duas etapas sendo uma delas em laboratório e a segunda em condições de campo. Em laboratório,

\footnotetext{
${ }^{1}$ Recebido para publicação em 18/02/99 e na forma revisada em 25/09/99.

${ }^{2}$ Prof $^{\circ}$ Assistente Dr., FCA/UNESP. C.P. 237, CEP: 18603-970, Botucatu/SP.

${ }^{3}$ Dr. em Agronomia, FCA/UNESP. C.P. 237, CEP: 18603-970, Botucatu/SP.
} 
determinou-se a tensão superficial de soluções de glyphosate e do espalhante "condensado de alcoolfenóis com óxido de eteno e sulfonados orgânicos". Foram utilizados os produtos comerciais Roundup (360 g e.a. / 1) e Aterbane (450 g i.a. / 1), respectivamente.

A tensão superficial foi medida pesandose as gotas formadas através da lenta passagem do líquido por capilares de vidro com diâmetro conhecido. Foram consideradas as combinações entre cinco concentrações de glyphosate $(0 ; 1 ; 2$; 3,5 e $5 \%$ de p.c.) e seis concentrações de espalhante adesionante $(0 ; 0,1 ; 0,2 ; 0,3 ; 0,5 ; 0,75$ e $1,0 \%$ de p.c.). Avaliou-se, também, a tensão superficial de onze tratamentos com 0,005 a $3 \%$ (de p.c.) do espalhante e nove tratamentos com 0,05 a $5 \%$ (de p.c.) do herbicida. Utilizou-se o delineamento inteiramente casualizado com 15 repetições. Aos resultados obtidos foram ajustadas equações de regressão segundo o modelo de Mitscherlich (Y = a. $\left.\left(1-10^{-\mathrm{c} .(\mathrm{X}+\mathrm{b})}\right)\right)$.

Em campo, avaliou-se a eficácia do glyphosate, aplicado em doses entre 1,2 e 7,2 1 p.c. / ha e associado a distintas concentrações de espalhante adesionante $(0 ; 0,1 ; 0,2 ; 0,3 ; 0,5$; 0,75 e $1,0 \%$ de p.c.), no controle de Brachiaria decumbens e Panicum maximum. Em um tratamento adicional, determinou-se o efeito do espalhante adesionante, aplicado isoladamente em concentrações entre 0,08 e $1,17 \%$ de p.c., sobre as gramíneas.

A variação das doses do glyphosate e das concentrações do espalhante (somente no tratamento adicional) foi feita utilizando-se um pulverizador logarítmico. $\mathrm{O}$ equipamento foi construído segundo o modelo descrito por Silva (1996). As principais características deste experimento são descritas a seguir: as plantas daninhas estavam no estádio de florescimento e não estavam sob estresse hídrico e térmico; o delineamento estatístico utilizado foi 0 inteiramente casualizado com três repetições; as parcelas continham $24,8 \mathrm{~m}$ de comprimento por $2 \mathrm{~m}$ de largura; avaliou-se 18 doses na extensão da parcela, sendo 54 doses por concentração do espalhante e 378 por espécie de planta daninha; utilizou-se um pulverizador costal a pressão de $\mathrm{CO}_{2}$ a pressão de $1,75 \mathrm{~kg} / \mathrm{cm}^{2}$ e bicos teejet 80.02 XR, com um consumo de calda de 242 1/ha; por ocasião da aplicação a umidade relativa do ar era de $45 \%$ e a temperatura do ar de $28 \mathrm{C}$; a primeira chuva ocorreu em três dias, com $7 \mathrm{~mm}$ de precipitação; avaliou-se visualmente o controle com notas variando de 0 a $100 \%$; e encerrouse o experimento com 41 dias após a aplicação dos tratamentos. Exemplos de curvas de variação de doses ou concentrações e as equações para determinação destas características em cada ponto das parcelas, são apresentadas na Figura 1.

Aos resultados de porcentagem de controle (médias dos três avaliadores) foram ajustadas equações de regressão segundo o modelo logístico $\left(\mathrm{Y}=\mathrm{a} /\left(1+10^{(-\mathrm{b}-\mathrm{c} \cdot \mathrm{X})}\right)\right.$. Ajustou-se, também, curvas gerais de controle considerando conjuntamente todos os resultados obtidos para cada espécie.

\section{RESULTADOS E DISCUSSÃO}

\section{Avaliações da tensão superficial}

Na Tabela 1, são apresentados os resultados referentes às análises de regressão entre as tensões superficiais e as concentrações do herbicida e do espalhante adesionante. Os coeficientes de determinação das equações e o coeficiente de variação do experimento $(0,42 \%)$ indicam que os resultados apresentaram elevada precisão. As equações de regressão obtidas são representadas nas Figuras 2 e 3 .

Observa-se que o espalhante adesionante mostrou-se muito mais eficiente que o herbicida em termos de redução da tensão superficial. Os coeficientes de eficácia (parâmetro "c" do modelo de Mitscherlich) foram de 13,2377 e 44,4697 e as tensões mínimas alcançadas foram da ordem de e 47 e $28 \mathrm{mN} / \mathrm{m}$ (mili Newtons/metro), respectivamente. 


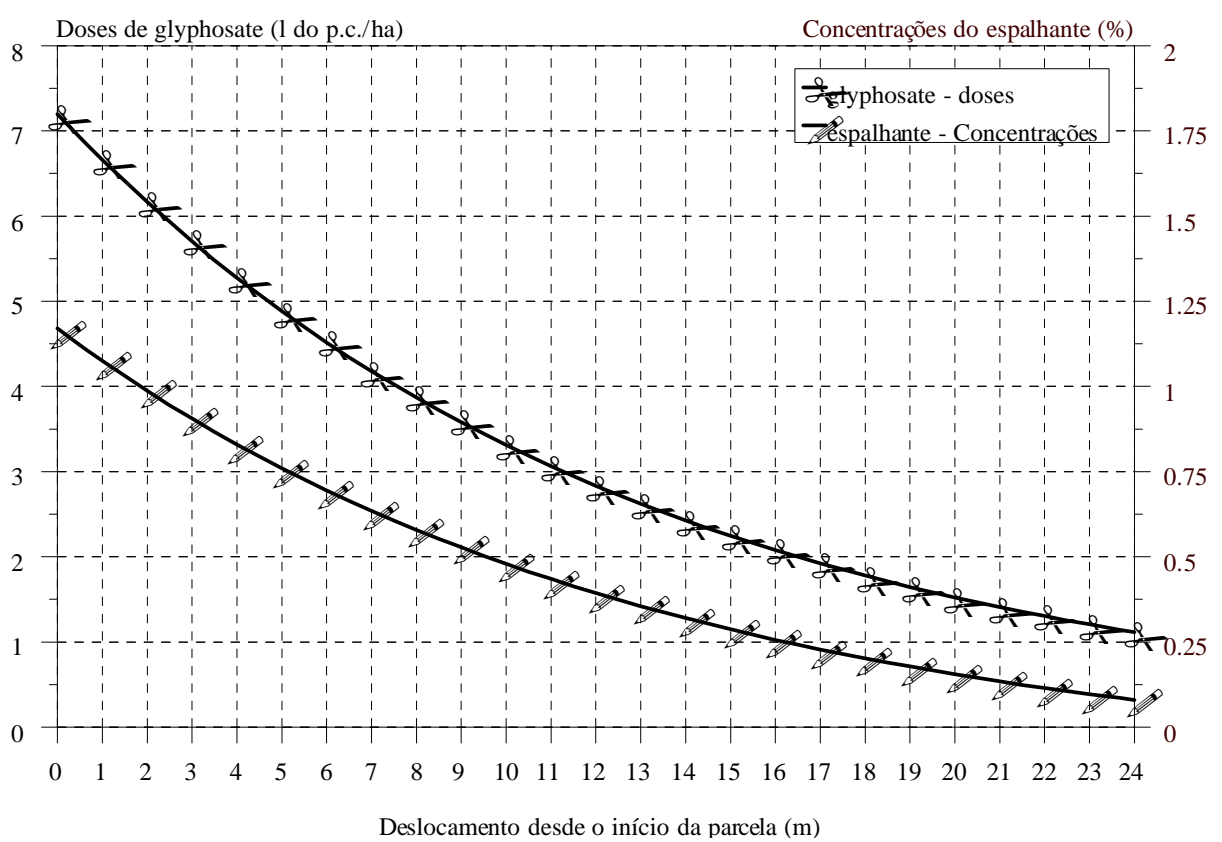

$$
\begin{array}{lr}
\mathrm{D}=\text { Dmp } \cdot(\mathrm{Vp} / \mathrm{Vrm}) \cdot 10^{(-0,2426 \cdot \mathrm{d} / \mathrm{Vrm})} & \mathbf{r}^{2}=0,99547 \\
\mathrm{C}=\mathrm{Cmp} \cdot(\mathrm{Vp} / \mathrm{Vrm}) \cdot 10^{(-0,2426 \cdot \mathrm{d} / \mathrm{Vrm})} & \mathbf{r}^{2}=\mathbf{0 , 9 9 5 4 7}
\end{array}
$$

onde,

$\mathrm{D}=$ Dose de glyphosate (1 de p.c. / ha),

$\mathrm{C}=$ Concentração do espalhante adesionante (\% de p.c.),

Dmp = Dose máxima prevista (1 de p.c. $/$ ha),

Cmp = Concentração máxima prevista (\% de p.c.)

$\mathrm{Vp}=$ Velocidade prevista $(0,8 \mathrm{~m} / \mathrm{s})$,

Vrm $=$ Velocidade real média $(\mathrm{m} / \mathrm{s})$,

$\mathrm{d}$ = Deslocamento após o início da pulverização da parcela $(\mathrm{m})$.

FIGURA 1. Exemplos de curvas representando a variação de doses do herbicida ou concentrações do espalhante em função da distância até o início da parcela (acima). Equações de regressão utilizadas para cálculo das doses de glyphosate ou concentrações do espalhante adesionante em cada ponto das parcelas (abaixo). 
TABELA 1. Resultados referentes às análises de regressão entre as tensões superficiais e concentrações do espalhante adesionante ou do glyphosate, nas soluções estudadas. Botucatu/SP, 1.995.

\begin{tabular}{|c|c|c|c|c|c|c|c|c|}
\hline \multirow[t]{2}{*}{ Características } & \multicolumn{7}{|c|}{ Concentrações do espalhante adesionante (\% de p.c.) } & \multirow[t]{2}{*}{ Espalhante } \\
\hline & $0 \%$ & $0,1 \%$ & $0,2 \%$ & $0,3 \%$ & $0,5 \%$ & $0,75 \%$ & $1,0 \%$ & \\
\hline Modelo utilizado & Mitscherlich & Mitscherlich & Mitscherlich & Mitscherlich & Mitscherlich & Mitscherlich & Mitscherlich & Mitscherlich \\
\hline $\mathrm{x}$ & [glyphosate] & [glyphosate] & [glyphosate] & [glyphosate] & [glyphosate] & [glyphosate] & [glyphosate] & [espalhante] \\
\hline $\mathrm{y}$ & $72,6-\mathrm{TS}$ & TS & $\mathrm{TS}$ & $\mathrm{TS}$ & TS & $\mathrm{TS}$ & $\mathrm{TS}$ & $72,6-\mathrm{TS}$ \\
\hline a & 25,21 & 44,35 & 43,36 & 42,67 & 41,88 & 41,44 & 41,12 & 40,16 \\
\hline $\mathrm{b}$ & - & 0,7112 & 1,2079 & 1,7483 & 2,9372 & 4,5942 & 6,3270 & - \\
\hline $\mathrm{c}$ & 13,2377 & 0,7524 & 0,4637 & 0,3305 & 0,2035 & 0,1325 & 0,0980 & 44,4697 \\
\hline $\mathrm{r}^{2}$ & 0,9934 & 0,9992 & 0,9996 & 0,9999 & 0,9965 & 0,9920 & 0,9919 & 0,9816 \\
\hline $\mathrm{F}$ & $149,99 * *$ & $1.251,80 * *$ & $2.262,96^{* *}$ & $14.604,45^{* *}$ & $284,15^{* *}$ & $124,24 * *$ & $123,19 * *$ & $1.412 .393,93 * *$ \\
\hline
\end{tabular}

- x e y: variáveis do modelo; a, b e c: parâmetros do modelo. ** significativo ao nível de $1 \%$ de probabilidade. 
Efeito de concentrações de espalhante adesionante e doses de glyphosate no controle de Brachiaria decumbens e Panicum maximum

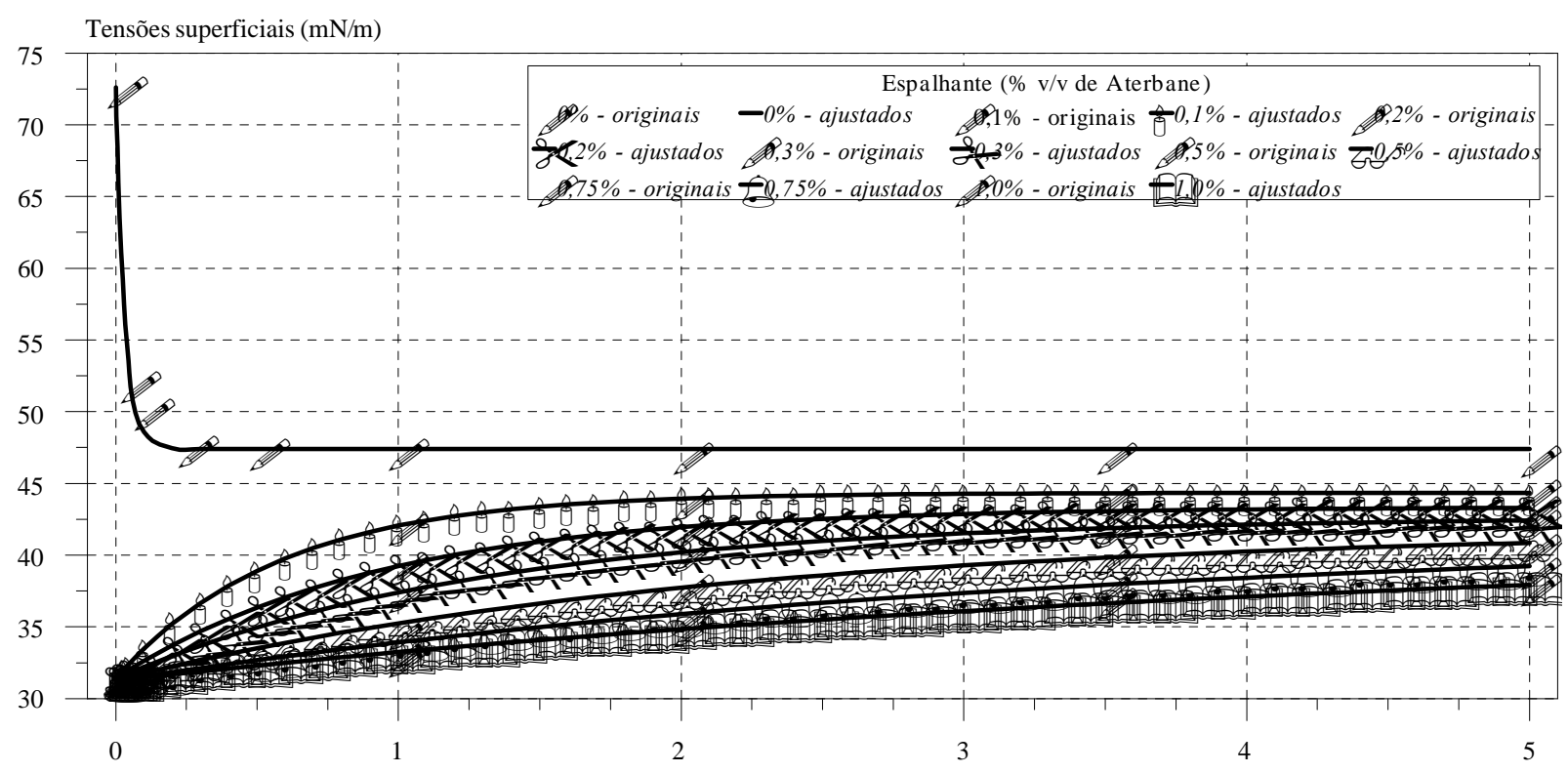

Concentrações de glyphosate (\% v/v de p.c./ha)

FIGURA 2. Tensões superficiais em função da concentração de glyphosate (\% do p.c. Roundup/ha). Concentrações do espalhante adesionante: 0 a 1,0\% v/v do produto comercial Aterbane. Dados originais e ajustados segundo o modelo de Mitscherlich.

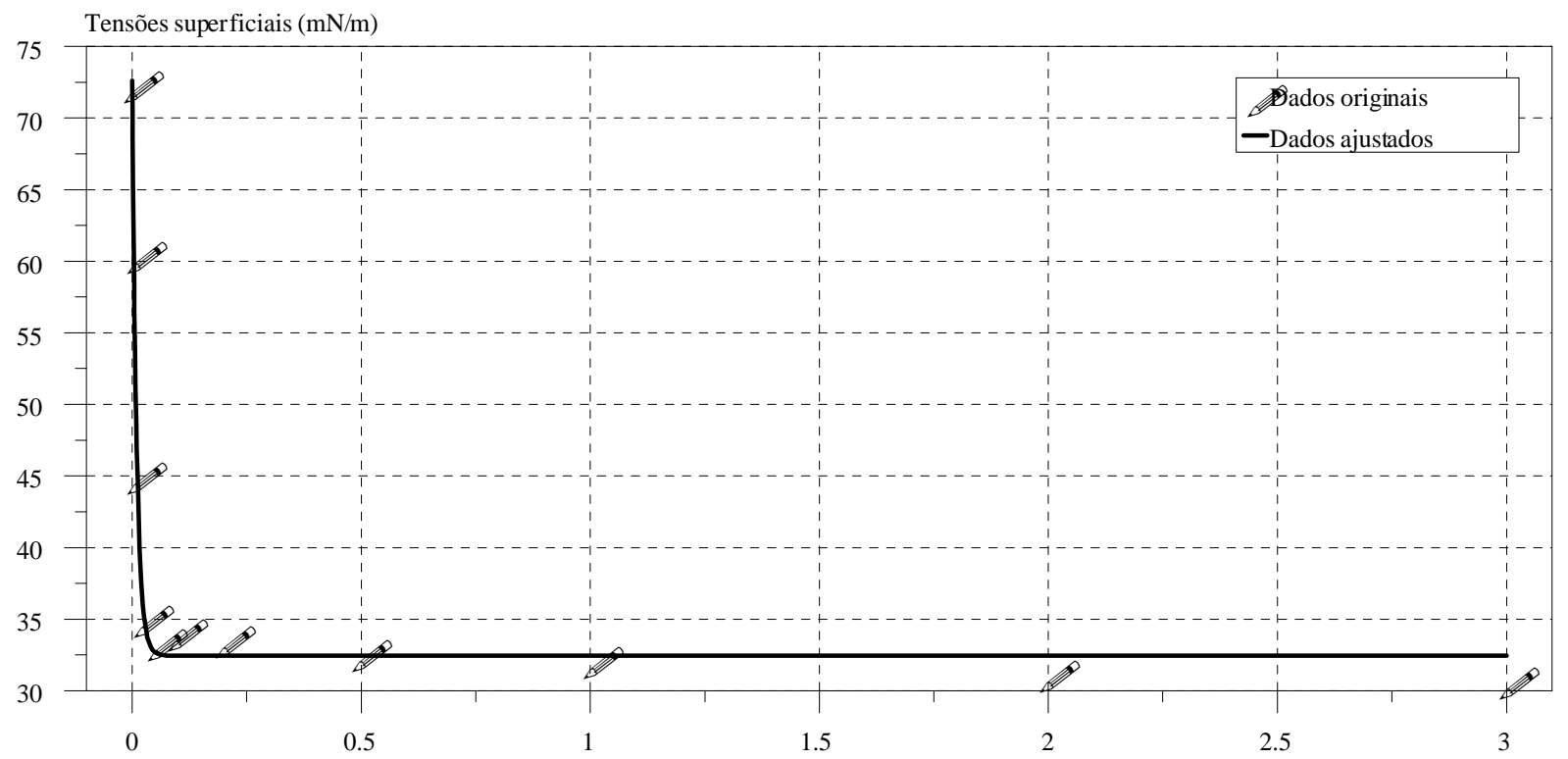

Concentrações de espalhante (\% v/v do p.c. Aterbane / ha)

FIGURA 3. Tensões superficiais em função da concentração de espalhante adesionante ( 0 a 3,0\% v/v do produto comercial Aterbane). 
A adição do glyphosate (Roundup) às soluções do espalhante promoveram elevações na tensão superficial das mesmas. Tal efeito foi tão mais intenso quanto maior a quantidade adicionada do herbicida. A análise dos trabalhos de Mendonça et al. (1996) e Costa (1997) indica que o espalhante adesionante MON 0818 (do grupo das tallow aminas e com caráter catiônico), presente no produto comercial Roundup, mostra-se antagônico aos componentes do espalhante adesionante estudado neste trabalho, reduzindolhes a eficácia. Costa (1997) verificou também que o ingrediente ativo glyphosate aumenta a eficácia do espalhante testado (Aterbane) em termos de redução de tensão superficial. Neste trabalho ficou evidente que, quando se considera a adição da mistura de glyphosate e MON 0818 (produto comercial Roundup) a soluções do espalhante (Aterbane), prevalece o efeito antagonístico entre os surfatantes.

\section{Eficácia do glyphosate no controle de $B$. decumbens e $P$. maximum}

No tratamento adicional, com aplicação do espalhante adesionante, isoladamente, não foram verificadas injúrias às espécies estudadas. Neste tratamento as tensões superficiais praticamente não variaram, tendo oscilado entre $32,45 \mathrm{e}$ $32,44 \mathrm{mN} / \mathrm{m}$.

$\mathrm{Na}$ Tabela 2 são apresentados os resultados referentes às análises de regressão entre as porcentagens de controle $\mathrm{e}$ as doses de glyphosate nos vários tratamentos. Os valores de $\mathrm{F}$ e $\mathrm{r}^{2}$ foram, de modo geral, bastante altos, indicando elevada precisão experimental.

O parâmetro "a" corresponde à máxima porcentagem de controle que poderia ser obtida para cada tratamento. Para as duas espécies, valores de "a" iguais ou próximos a $100 \%$ só foram verificados para os tratamentos com 0;0,1 e $0,2 \%$ do espalhante. Concentrações superiores a estas reduziram o máximo potencial de controle das duas gramíneas pelo glyphosate.

As equações obtidas, além das curvas representando as tensões superficiais para cada dose de glyphosate em cada tratamento são apresentadas nas Figuras 4 a 15 . As tensões superficiais foram calculadas a partir das equações obtidas na primeira parte do trabalho. Nas Tabelas 3 e 5 são apresentadas as doses do herbicida necessárias para que fossem alcançadas porcentagens de controle das gramíneas entre $70 \mathrm{e}$ 90\%. Nas Tabelas 4 e 6, tais doses são expressas em porcentagem das respectivas doses necessárias no tratamento com aplicação do herbicida isoladamente. Esta amplitude de porcentagens de controle foi escolhida considerando dois aspectos, a utilidade prática e o fato de ser possível alcançar qualquer ponto da mesma em qualquer concentração do espalhante, bastando para isso, ajustar a dose de glyphosate.

Verifica-se, para todos os tratamentos e também para as curvas gerais de controle, que a Brachiaria decumbens foi mais sensível ao glyphosate que o Panicum maximum. A equação linear de regressão entre as doses do herbicida necessárias para que fossem alcançadas porcentagens de controle pré-fixadas das duas espécies apresentou $\mathrm{r}^{2}$ de $0,994 \mathrm{e}$ indicou a necessidade de uso de doses $24,05 \%$ superiores para o Panicum maximum.

Observa-se que as tensões superficiais (Figura 11) variaram acentuadamente, tanto entre quanto dentro dos tratamentos. Quanto menor a concentração do espalhante, mais expressivo foi o antagonismo com o glyphosate (Roundup), em termos de ação redutora de tensão, acentuando a inclinação das curvas.

A análise das Figuras 12 e 13 indica que os tratamentos com 0,1 e $0,2 \%$ de espalhante, foram os que exigiram menores doses para que fossem alcançadas porcentagens de controle entre 70 e $90 \%$ para as duas espécies. Contudo, para $B$. decumbens, os tratamentos com 0 e $0,2 \%$ do espalhante proporcionaram porcentagens de controle bastante próximas em toda faixa de doses estudada. Tais observações podem ser comprovadas pela análise das Tabelas 3 e 5 e, sobretudo, das Tabelas 4 e 6. 
TABELA 2. Parâmetros do modelo de logístico, valores de "F" e coeficientes de determinação das equações de regressão entre doses de glyphosate e porcentagens de controle de Brachiaria decumbens e Panicum maximum. Botucatu/SP, 1.995.

\begin{tabular}{|c|c|c|c|c|c|c|c|c|c|}
\hline \multirow[t]{2}{*}{ Espécie } & \multirow[t]{2}{*}{ Característica } & \multicolumn{7}{|c|}{ Concentrações do espalhante adesionante (\% de p.c.) } & \multirow{2}{*}{$\begin{array}{c}\text { Total } \\
0 \%-1 \%\end{array}$} \\
\hline & & $0 \%$ & $0,1 \%$ & $0,2 \%$ & $0,3 \%$ & $0,5 \%$ & $0,75 \%$ & $1,0 \%$ & \\
\hline \multirow{5}{*}{ B. decumbens } & $\bar{a}$ & 98,38 & 97,66 & 100,00 & 95,48 & 94,72 & 93,65 & 95,42 & 96,69 \\
\hline & $\mathrm{b}$ & $-1,9013$ & $-2,2030$ & $-1,7666$ & $-1,9639$ & $-2,1115$ & $-1,4638$ & $-1,4677$ & $-1,8032$ \\
\hline & $\mathrm{c}$ & 0,6216 & 0,7762 & 0,5864 & 0,6527 & 0,6983 & 0,5228 & 0,5102 & 0,6109 \\
\hline & $\mathrm{r}^{2}$ & 0,9289 & 0,9658 & 0,9324 & 0,9234 & 0,9380 & 0,9222 & 0,8806 & 0,9187 \\
\hline & $\mathrm{F}$ & $333,08^{* *}$ & $720,54 * *$ & $351,81 * *$ & $307,36^{* *}$ & $385,63^{* *}$ & $302,07 * *$ & $188,02 * *$ & $2.288,28 * *$ \\
\hline \multirow{5}{*}{ P. maximum } & $\bar{a}$ & 100,00 & 98,65 & 100,00 & 92,35 & 93,99 & 93,80 & 93,39 & 95,91 \\
\hline & $\mathrm{b}$ & $-1,9724$ & $-2,3597$ & $-2,0134$ & $-1,9150$ & $-1,7501$ & $-1,5717$ & $-1,6009$ & $-1,8636$ \\
\hline & $\mathrm{c}$ & 0,4920 & 0,6425 & 0,5373 & 0,5308 & 0,4884 & 0,4460 & 0,4666 & 0,5094 \\
\hline & $\mathrm{r}^{2}$ & 0,9604 & 0,9195 & 0,9057 & 0,9337 & 0,9164 & 0,9356 & 0,8641 & 0,8827 \\
\hline & $\mathrm{F}$ & $617,94 * *$ & $291,39 * *$ & $244,94 * *$ & $359,29 * *$ & $279,68^{* *}$ & $370,33 * *$ & $82,58 * *$ & $1.585,31 * *$ \\
\hline
\end{tabular}

Obs.: a, b e c são parâmetros do modelo logístico. ** significativo ao nível de $1 \%$ de probabilidade. 


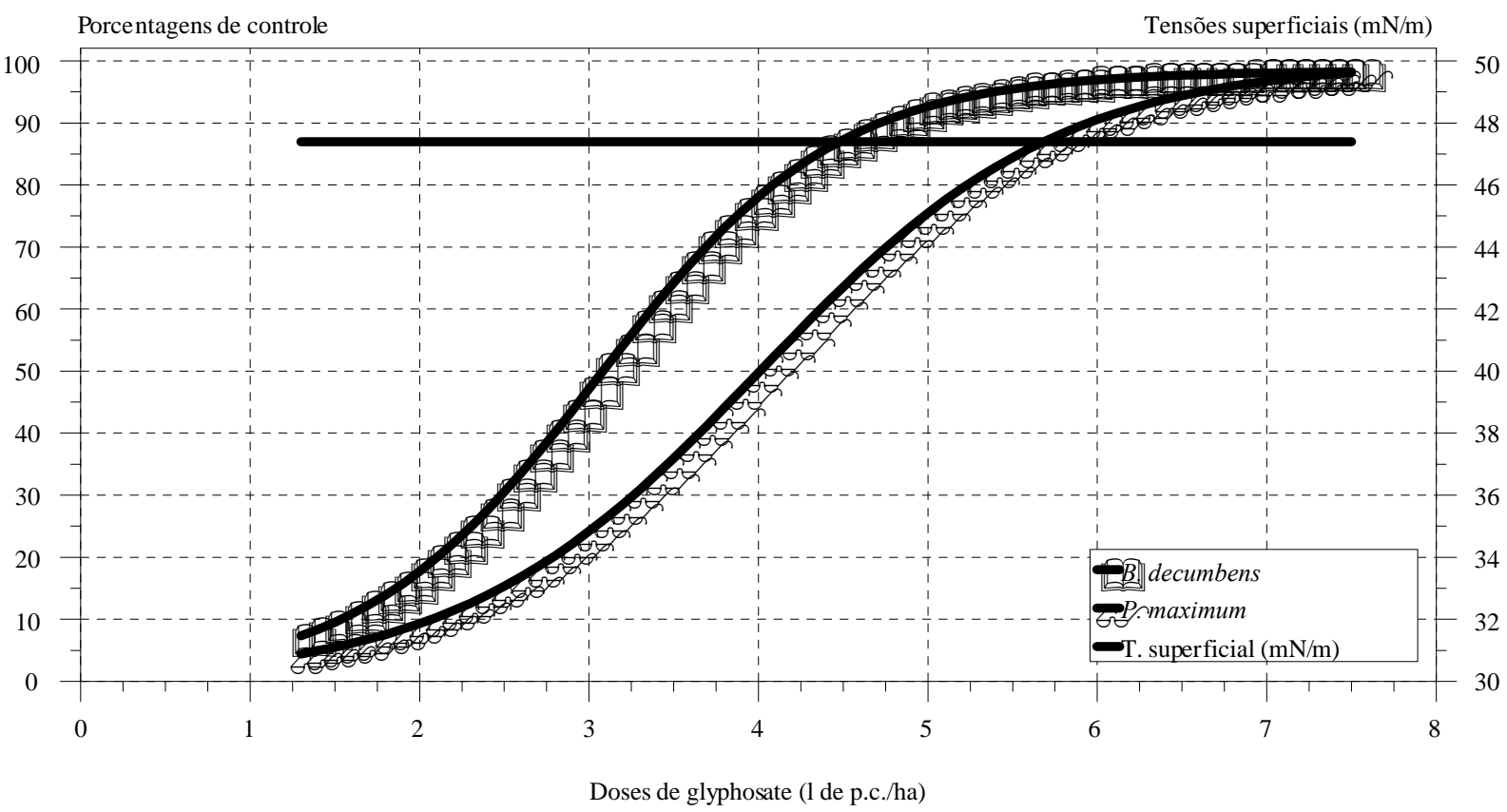

FIGURA 4. Tensões superficiais e porcentagens de controle de Brachiaria decumbens e Panicum maximum em função da dose de glyphosate (1 do p.c. Roundup/ha). Concentração do espalhante adesionante: $0 \% \mathrm{v} / \mathrm{v}$ do produto comercial Aterbane.

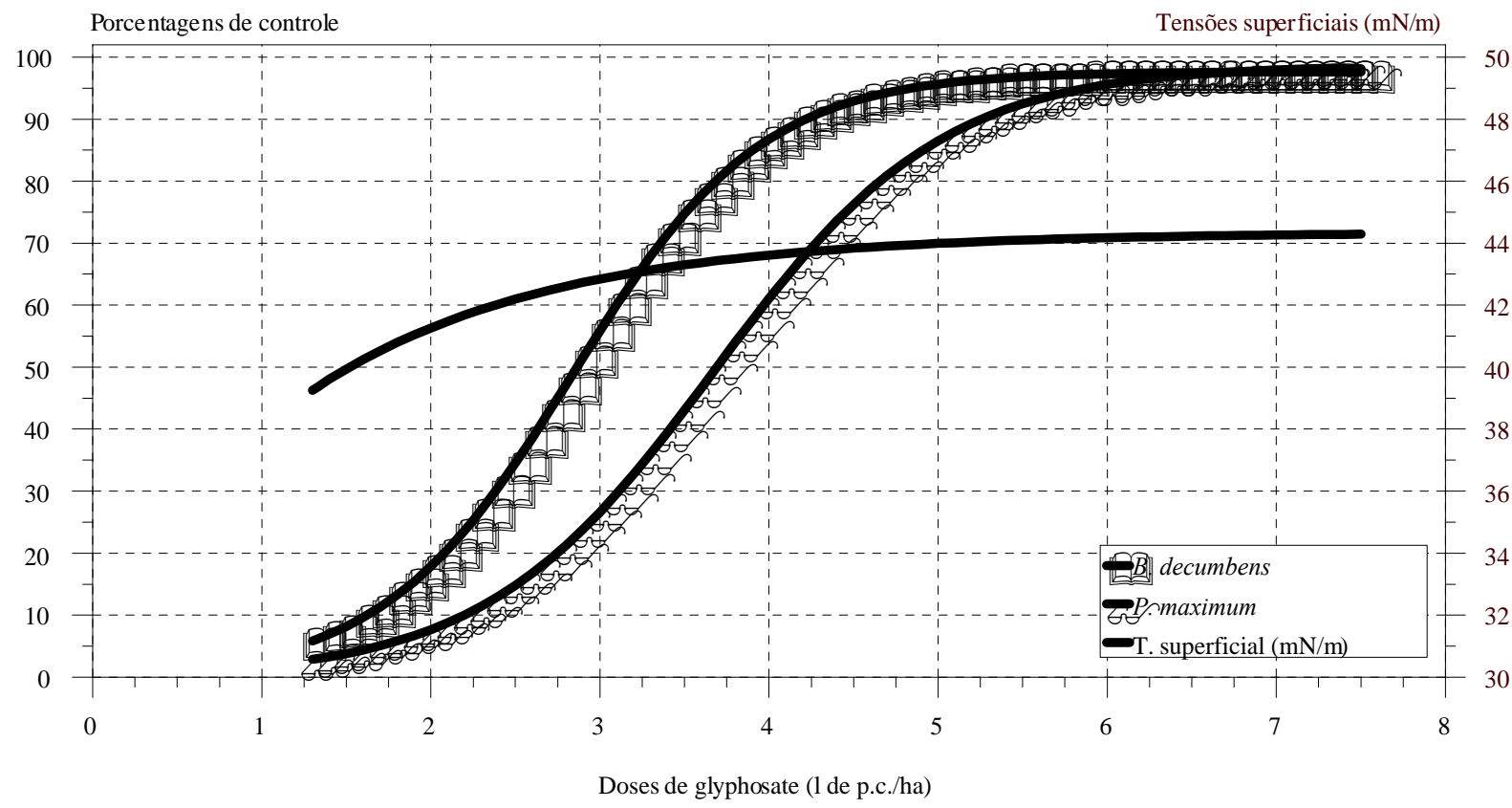

FIGURA 5. Tensões superficiais e porcentagens de controle de Brachiaria decumbens e Panicum maximum em função da dose de glyphosate (1 do p.c. Roundup/ha). Concentração do espalhante adesionante: $0,1 \% \mathrm{v} / \mathrm{v}$ do produto comercial Aterbane. 
Efeito de concentrações de espalhante adesionante e doses de glyphosate no controle de Brachiaria decumbens e Panicum maximum

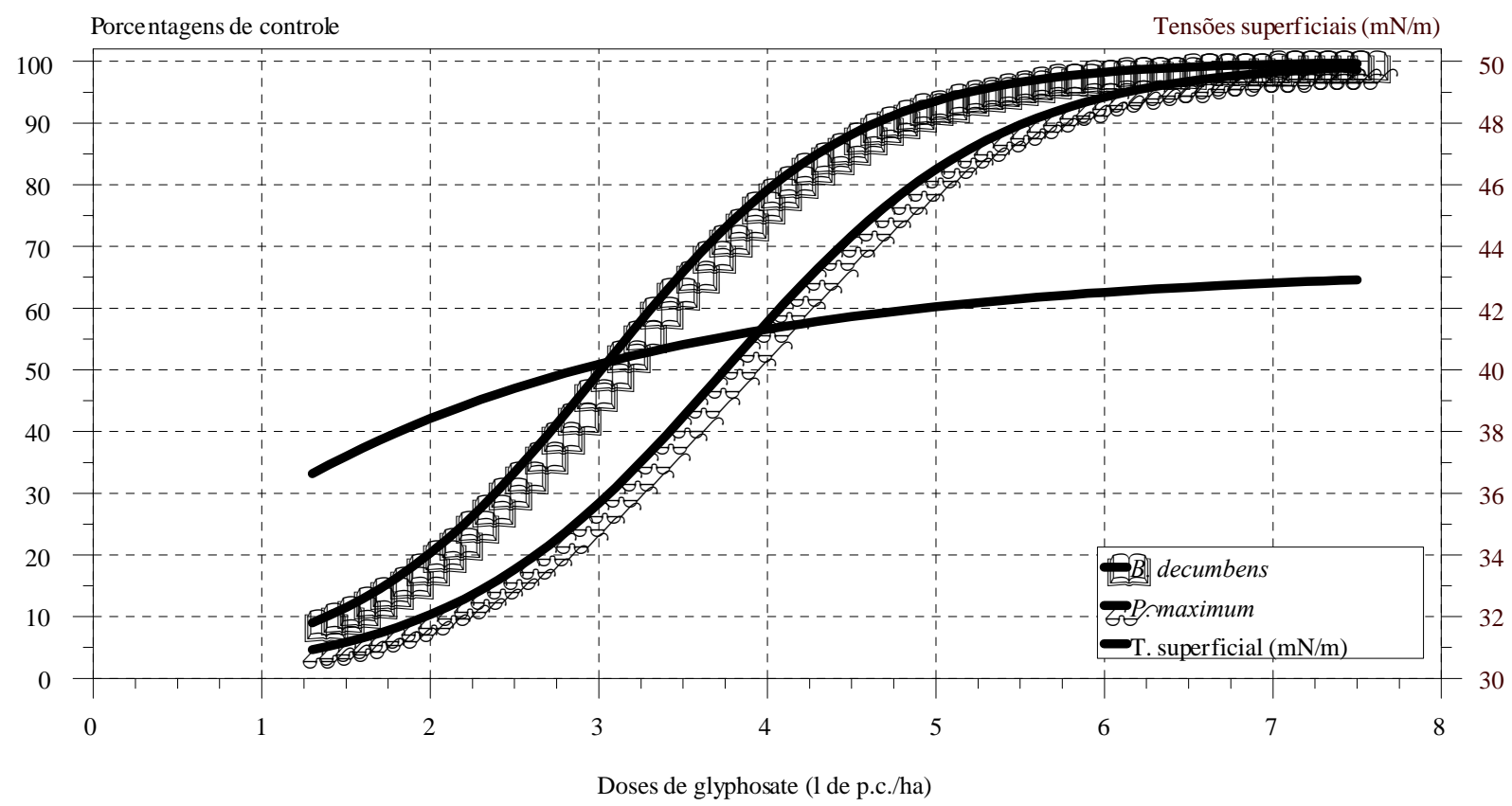

FIGURA 6. Tensões superficiais e porcentagens de controle de Brachiaria decumbens e Panicum maximum em função da dose de glyphosate (1 do p.c. Roundup/ha). Concentração do espalhante adesionante: $0,2 \% \mathrm{v} / \mathrm{v}$ do produto comercial Aterbane.

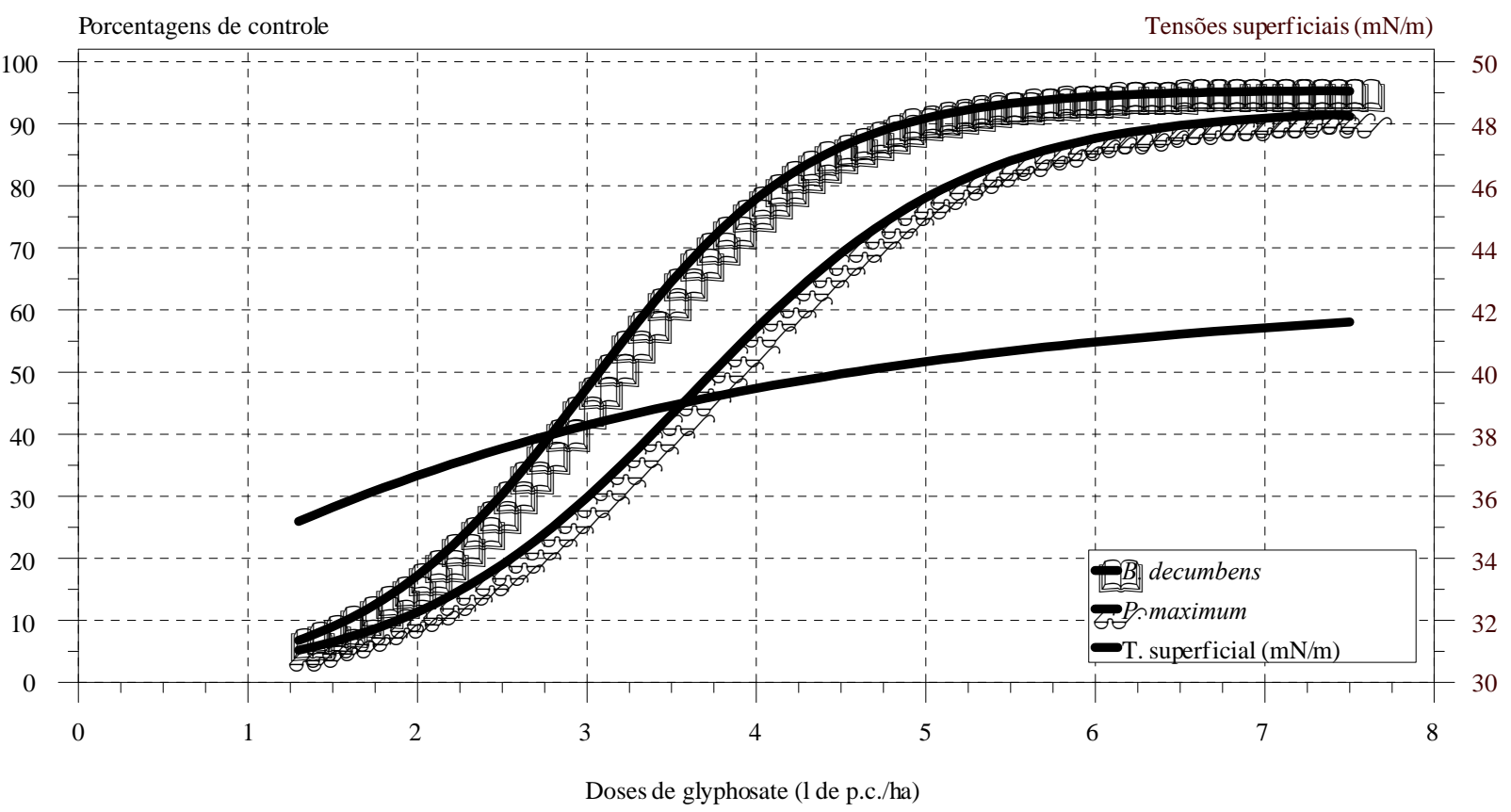

FIGURA 7. Tensões superficiais e porcentagens de controle de Brachiaria decumbens e Panicum maximum em função da dose de glyphosate (1 do p.c. Roundup/ha). Concentração do espalhante adesionante: $0,3 \% \mathrm{v} / \mathrm{v}$ do produto comercial Aterbane. 


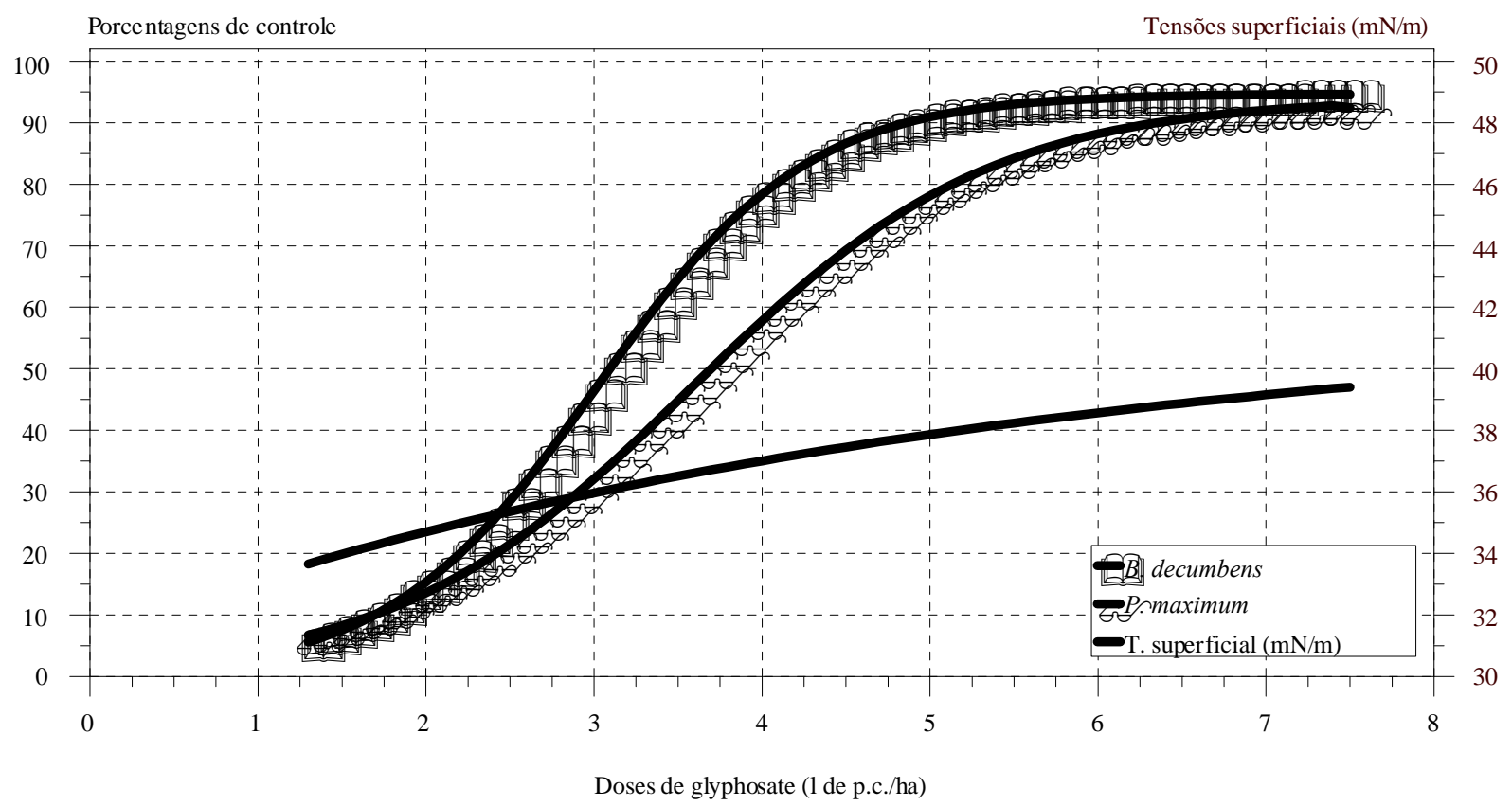

FIGURA 8. Tensões superficiais e porcentagens de controle de Brachiaria decumbens e Panicum maximum em função da dose de glyphosate (l do p.c. Roundup/ha). Concentração do espalhante adesionante: $0,5 \%$ $\mathrm{v} / \mathrm{v}$ do produto comercial Aterbane.

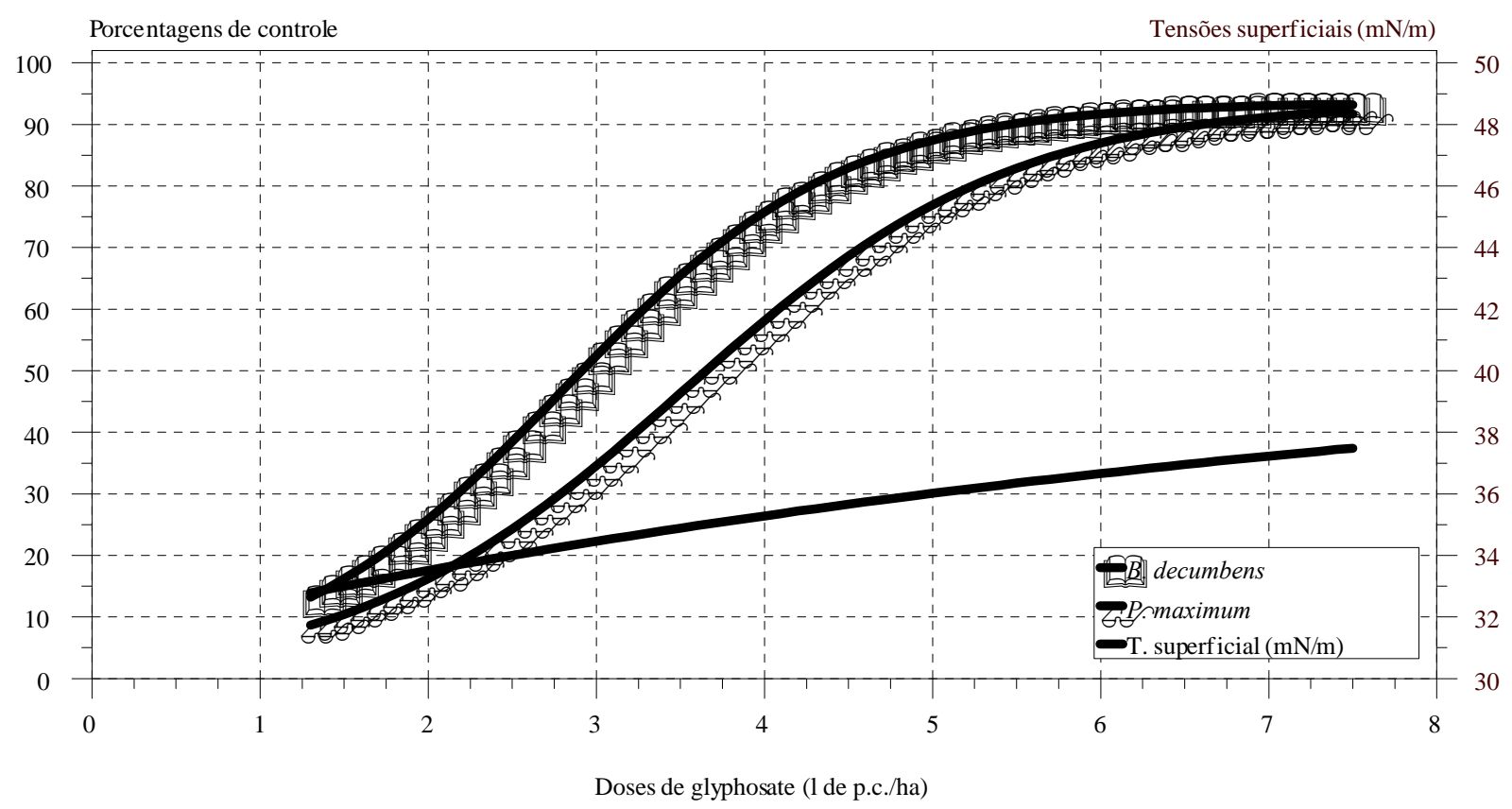

FIGURA 9. Tensões superficiais e porcentagens de controle de Brachiaria decumbens e Panicum maximum em função da dose de glyphosate (1 do p.c. Roundup/ha). Concentração do espalhante adesionante: $0,75 \% \mathrm{v} / \mathrm{v}$ do produto comercial Aterbane. 
Efeito de concentrações de espalhante adesionante e doses de glyphosate no controle de Brachiaria decumbens e Panicum maximum

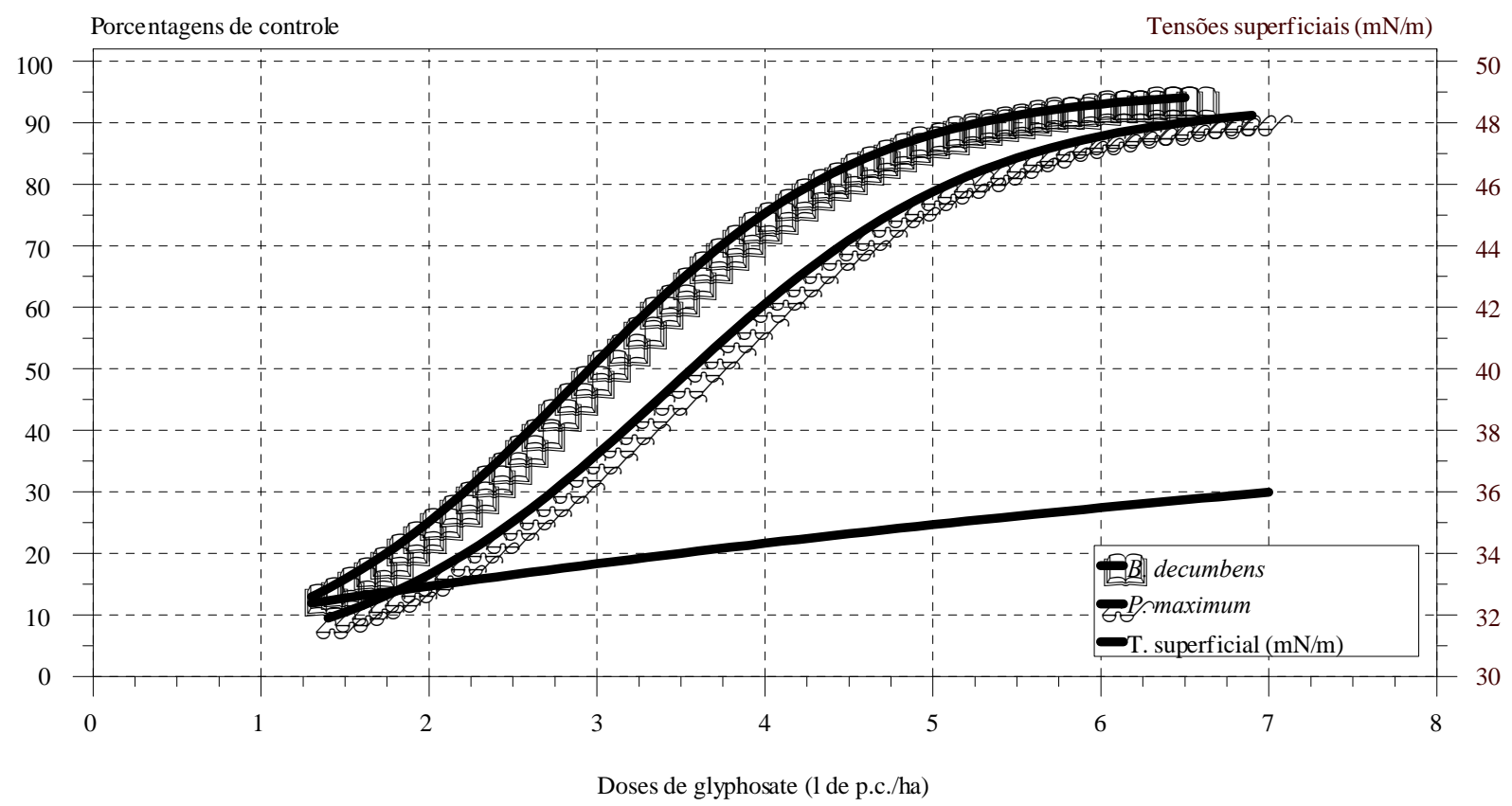

FIGURA 10. Tensões superficiais e porcentagens de controle de Brachiaria decumbens e Panicum maximum em função da dose de glyphosate (1 do p.c. Roundup/ha). Concentração do espalhante adesionante: $1,0 \% \mathrm{v} / \mathrm{v}$ do produto comercial Aterbane.

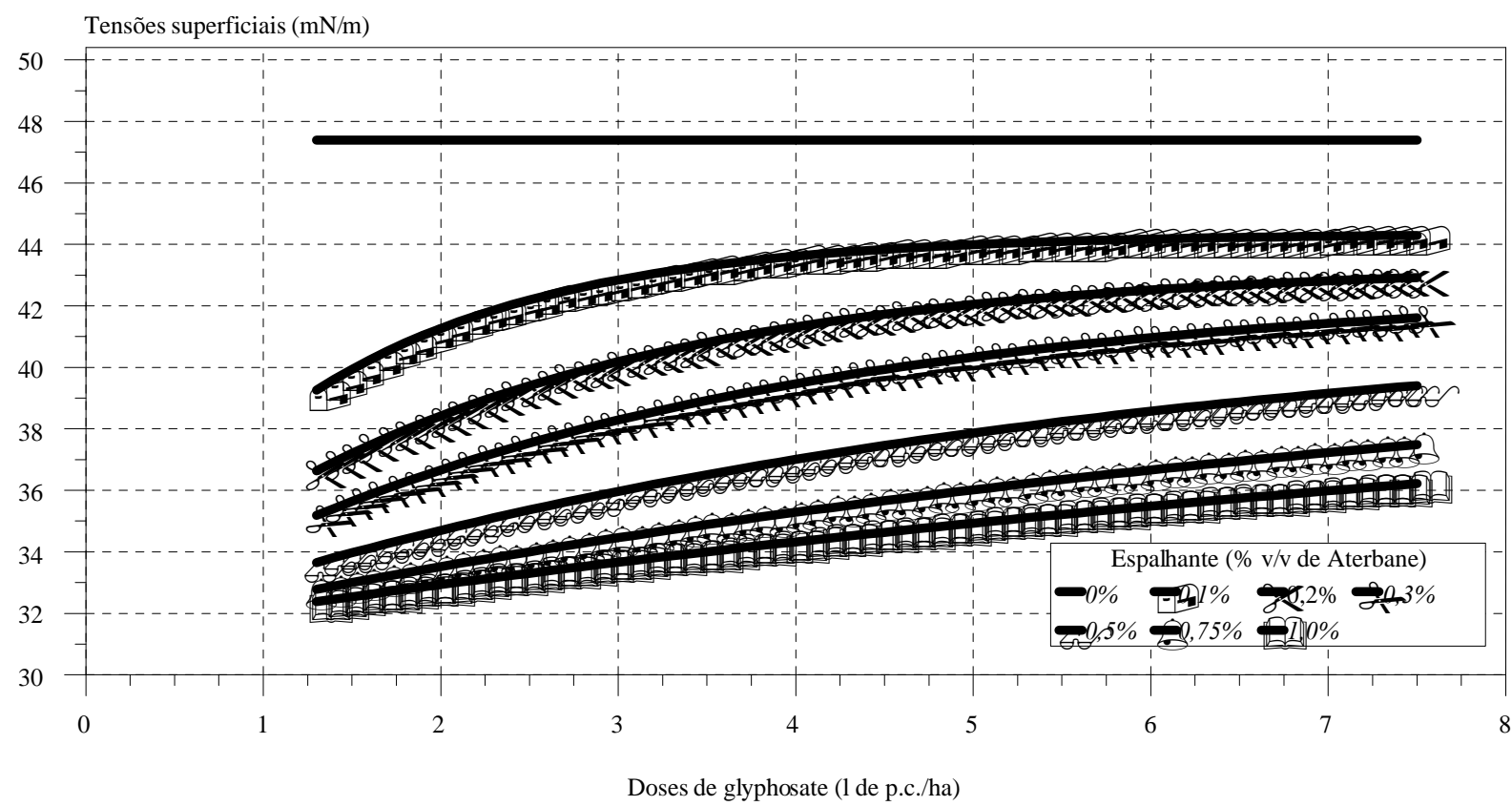

FIGURA 11. Tensões superficiais em função da dose de glyphosate (1 do p.c. Roundup/ha). Concentrações do espalhante adesionante: 0 a 1,0\% v/v do produto comercial Aterbane. 
Porcentagens de controle

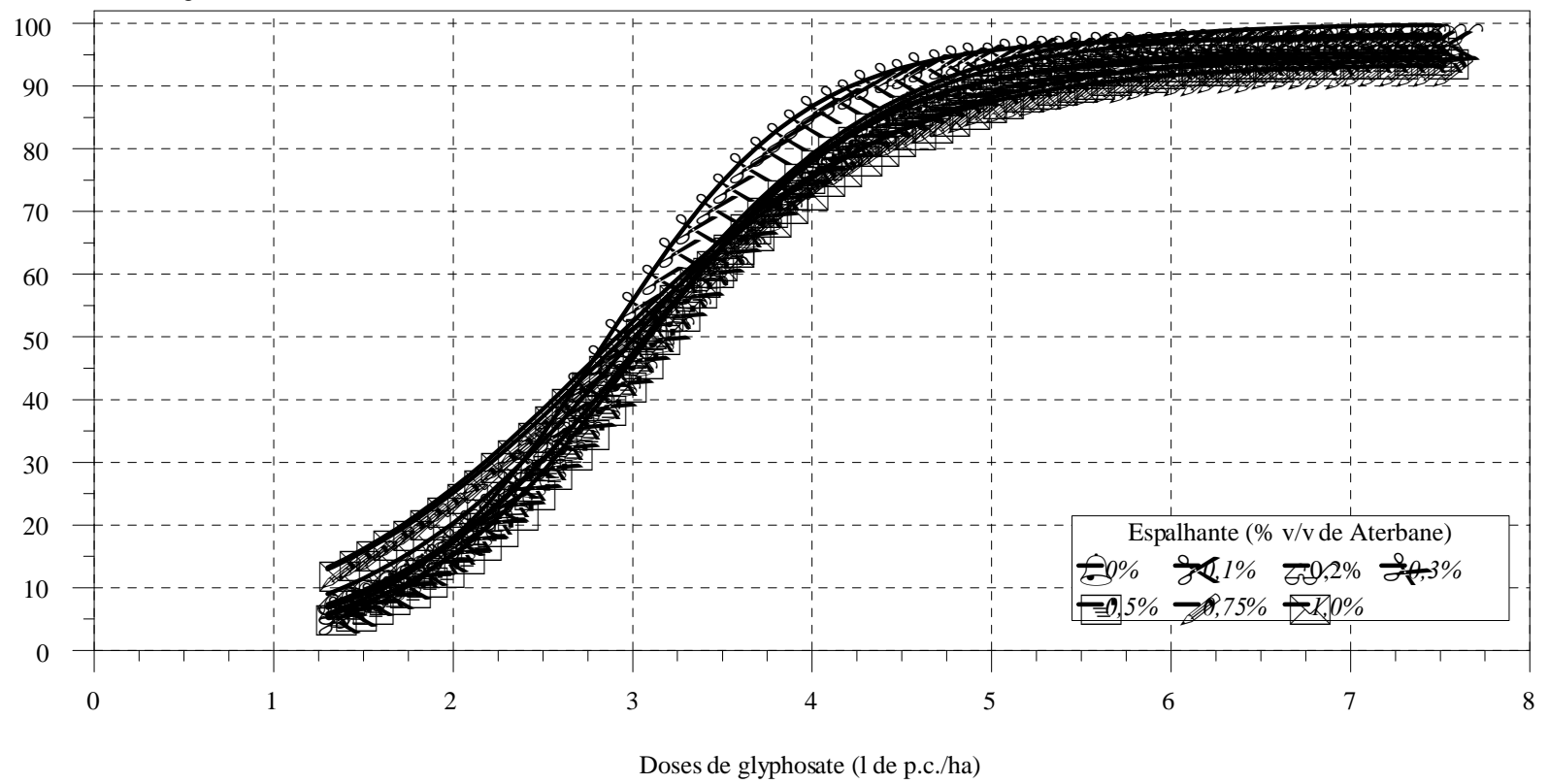

FIGURA 12. Porcentagens de controle de Brachiaria decumbens em função da dose de glyphosate (1 do p.c. Roundup/ha). Concentrações do espalhante adesionante: 0 a 1,0\% v/v do produto comercial Aterbane.

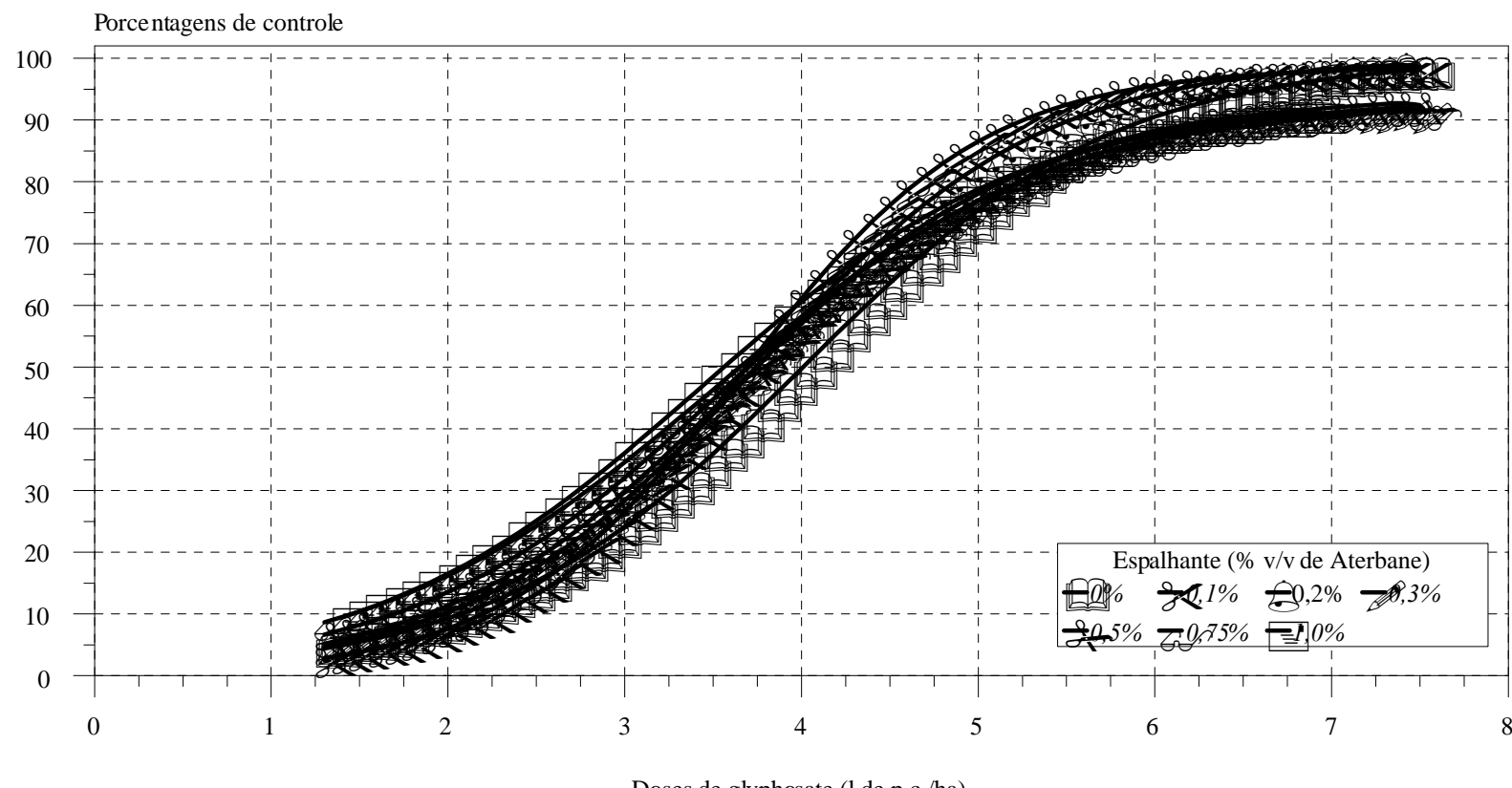

Doses de glyphosate (1 de p.c./ha)

FIGURA 13. Porcentagens de controle de Panicum maximum em função da dose de glyphosate (l do p.c. Roundup/ha). Concentrações do espalhante adesionante: 0 a $1,0 \% \mathrm{v} / \mathrm{v}$ do produto comercial Aterbane. 
Efeito de concentrações de espalhante adesionante e doses de glyphosate no controle de Brachiaria decumbens e Panicum maximum

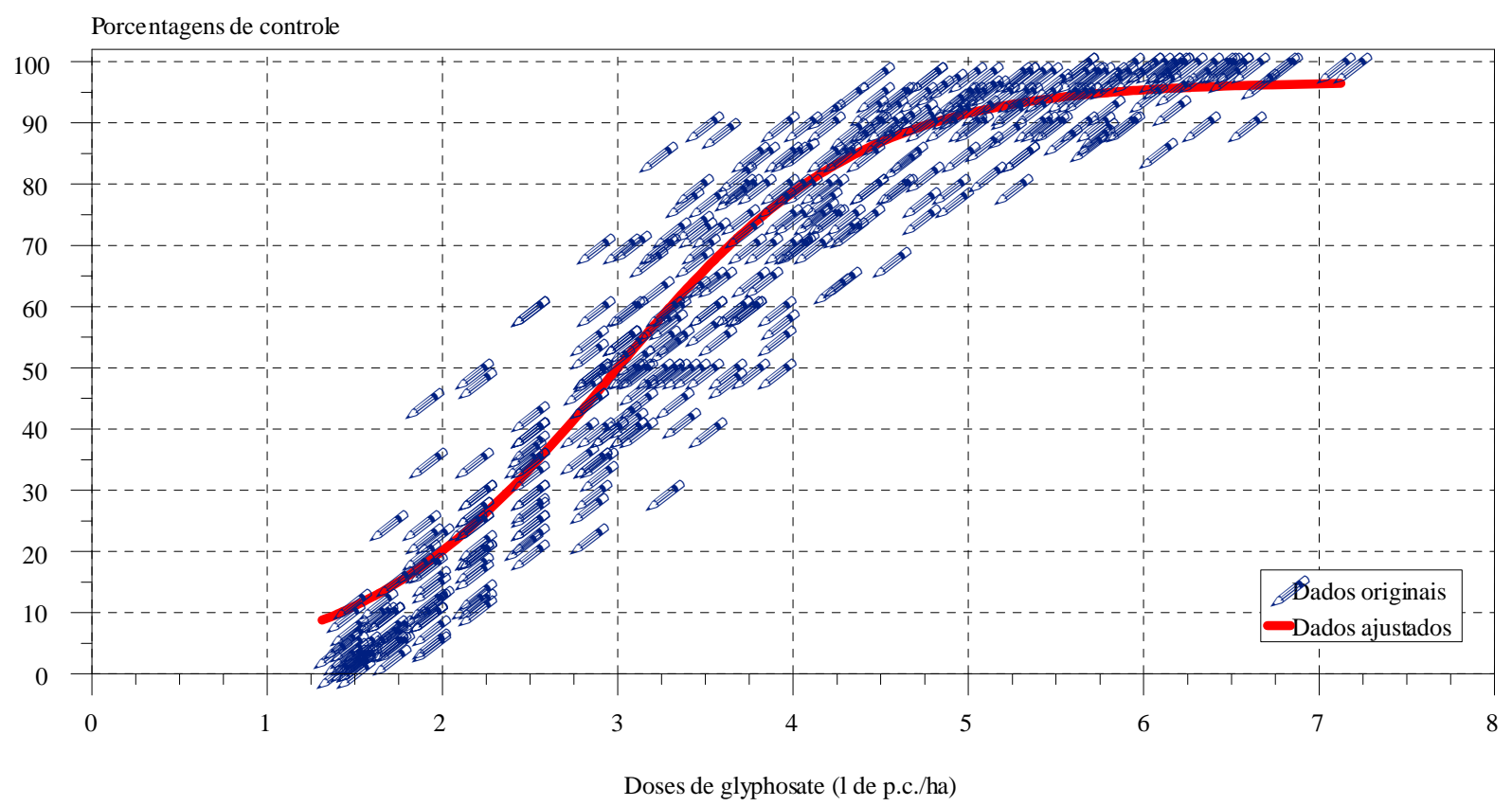

FIGURA 14. Porcentagens de controle de Brachiaria decumbens em função da dose de glyphosate (1 do p.c. Roundup/ha).

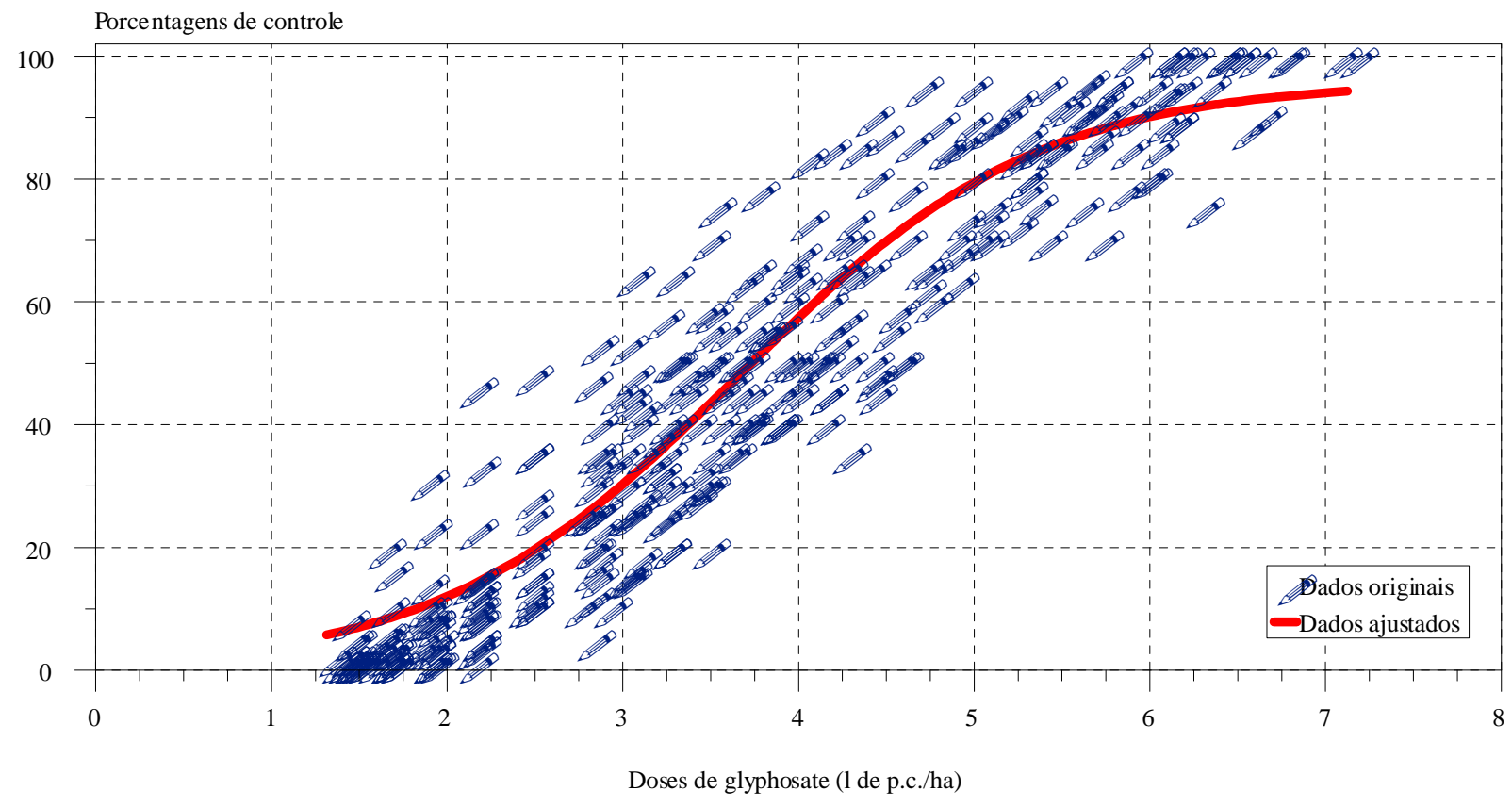

FIGURA 15. Porcentagens de controle de Panicum maximum em função da dose de glyphosate (l do p.c. Roundup/ha). 
TABELA 3. Doses de glyphosate, para que fossem alcançadas porcentagens de controle de B. decumbens entre 70\% e 90\%. Botucatu/SP, 1.995 .

\begin{tabular}{|c|c|c|c|c|c|c|c|c|c|}
\hline \multirow[t]{2}{*}{ Espécie } & \multirow[t]{2}{*}{$\%$ de controle } & \multicolumn{6}{|c|}{ Concentrações do espalhante adesionante (\% de p.c.) } & & \multirow{2}{*}{$\begin{array}{c}\text { Total } \\
0 \%-1 \%\end{array}$} \\
\hline & & $0 \%$ & $0,1 \%$ & $0,2 \%$ & $0,3 \%$ & $0,5 \%$ & $0,75 \%$ & $1,0 \%$ & \\
\hline \multirow{9}{*}{ B. decumbens } & 70,0 & 3,69 & 3,36 & 3,64 & 3,68 & 3,67 & 3,70 & 3,74 & 3,64 \\
\hline & 72,5 & 3,78 & 3,43 & 3,73 & 3,77 & 3,76 & 3,82 & 3,86 & 3,73 \\
\hline & 75,0 & 3,87 & 3,51 & 3,83 & 3,87 & 3,85 & 3,96 & 3,98 & 3,83 \\
\hline & 77,5 & 3,98 & 3,59 & 3,93 & 3,98 & 3,96 & 4,10 & 4,12 & 3,94 \\
\hline & 80,0 & 4,09 & 3,68 & 4,04 & 4,10 & 4,08 & 4,27 & 4,28 & 4,07 \\
\hline & 82,5 & 4,21 & 3,79 & 4,16 & 4,24 & 4,21 & 4,46 & 4,45 & 4,20 \\
\hline & 85,0 & 4,35 & 3,90 & 4,30 & 4,40 & 4,37 & 4,70 & 4,66 & 4,36 \\
\hline & 87,5 & 4,52 & 4,04 & 4,45 & 4,60 & 4,58 & 5,01 & 4,92 & 4,55 \\
\hline & 90,0 & 4,72 & 4,22 & 4,64 & 4,87 & 4,86 & 5,46 & 5,27 & 4,80 \\
\hline
\end{tabular}

Obs: doses expressas em litros do produto comercial Roundup / ha.

TABELA 4. Doses de glyphosate, para que fossem alcançadas porcentagens de controle de $B$. decumbens entre $70 \%$ e $90 \%$. Valores expressos em porcentagem da dose necessária para alcançar a mesmo nível de controle sem o uso de espalhante adesionante. Botucatu/SP, 1985.

\begin{tabular}{|c|c|c|c|c|c|c|c|c|c|}
\hline \multirow[t]{2}{*}{ Espécie } & \multirow[t]{2}{*}{$\%$ de controle } & \multicolumn{7}{|c|}{ Concentrações do espalhante adesionante (\% de p.c.) } & \multirow{2}{*}{$\begin{array}{c}\text { Total } \\
0 \%-1 \%\end{array}$} \\
\hline & & $0 \%$ & $0,1 \%$ & $0,2 \%$ & $0,3 \%$ & $0,5 \%$ & $0,75 \%$ & $1,0 \%$ & \\
\hline \multirow{9}{*}{ B. decumbens } & 70,0 & 100,00 & 91,00 & 98,66 & 99,77 & 99,50 & 100,32 & 101,33 & 98,57 \\
\hline & 72,5 & 100,00 & 90,78 & 98,73 & 99,86 & 99,49 & 101,18 & 102,07 & 98,76 \\
\hline & 75,0 & 100,00 & 90,57 & 98,79 & 99,98 & 99,52 & 102,14 & 102,86 & 98,97 \\
\hline & 77,5 & 100,00 & 90,35 & 98,83 & 100,15 & 99,60 & 103,21 & 103,72 & 99,21 \\
\hline & 80,0 & 100,00 & 90,14 & 98,85 & 100,37 & 99,76 & 104,46 & 104,69 & 99,49 \\
\hline & 82,5 & 100,00 & 89,93 & 98,84 & 100,70 & 100,03 & 105,99 & 105,81 & 99,83 \\
\hline & 85,0 & 100,00 & 89,73 & 98,78 & 101,17 & 100,50 & 107,99 & 107,19 & 100,26 \\
\hline & 87,5 & 100,00 & 89,54 & 98,64 & 101,93 & 101,33 & 110,86 & 109,00 & 100,84 \\
\hline & 90,0 & 100,00 & 89,39 & 98,36 & 103,26 & 102,96 & 115,79 & 111,68 & 101,73 \\
\hline
\end{tabular}


TABELA 5. Doses de glyphosate, para que fossem alcançadas porcentagens de controle de P. maximum entre 70\% e 90\%. Botucatu/SP, 1.995.

\begin{tabular}{|c|c|c|c|c|c|c|c|c|c|}
\hline \multirow[t]{2}{*}{ Espécie } & \multirow[t]{2}{*}{$\%$ de controle } & \multicolumn{7}{|c|}{ Concentrações do espalhante adesionante (\% de p.c.) } & \multirow{2}{*}{$\begin{array}{c}\text { Total } \\
0 \%-1 \%\end{array}$} \\
\hline & & $0 \%$ & $0,1 \%$ & $0,2 \%$ & $0,3 \%$ & $0,5 \%$ & $0,75 \%$ & $1,0 \%$ & \\
\hline \multirow{9}{*}{ P. maximum } & 70,0 & 4,76 & 4,28 & 4,43 & 4,54 & 4,54 & 4,57 & 4,45 & 4,51 \\
\hline & 72,5 & 4,86 & 4,36 & 4,53 & 4,67 & 4,66 & 4,72 & 4,59 & 4,62 \\
\hline & 75,0 & 4,98 & 4,45 & 4,64 & 4,81 & 4,80 & 4,87 & 4,74 & 4,75 \\
\hline & 77,5 & 5,10 & 4,55 & 4,75 & 4,96 & 4,96 & 5,04 & 4,91 & 4,88 \\
\hline & 80,0 & 5,23 & 4,66 & 4,87 & 5,14 & 5,13 & 5,23 & 5,09 & 5,04 \\
\hline & 82,5 & 5,38 & 4,77 & 5,00 & 5,35 & 5,34 & 5,46 & 5,32 & 5,21 \\
\hline & 85,0 & 5,54 & 4,91 & 5,15 & 5,61 & 5,58 & 5,73 & 5,59 & 5,41 \\
\hline & 87,5 & 5,73 & 5,07 & 5,32 & 5,97 & 5,90 & 6,09 & 5,94 & 5,66 \\
\hline & 90,0 & 5,95 & 5,26 & 5,52 & 6,59 & 6,35 & 6,61 & 6,48 & 5,98 \\
\hline
\end{tabular}

Obs: doses expressas em litros do produto comercial Roundup / ha.

TABELA 6. Doses de glyphosate, para que fossem alcançadas porcentagens de controle de $P$. maximum entre $70 \%$ e $90 \%$. Valores expressos em porcentagem da dose necessária para alcançar o mesmo nível de controle sem o uso de espalhante adesionante. Botucatu/SP, 1.995 .

\begin{tabular}{|c|c|c|c|c|c|c|c|c|c|}
\hline \multirow[t]{2}{*}{ Espécie } & \multirow[t]{2}{*}{$\%$ de controle } & \multicolumn{7}{|c|}{ Concentrações do espalhante adesionante (\% de p.c.) } & \multirow{2}{*}{$\begin{array}{c}\text { Total } \\
0 \%-1 \%\end{array}$} \\
\hline & & $0 \%$ & $0,1 \%$ & $0,2 \%$ & $0,3 \%$ & $0,5 \%$ & $0,75 \%$ & $1,0 \%$ & \\
\hline \multirow{9}{*}{ P. maximum } & 70,0 & 100,00 & 89,90 & 93,18 & 95,48 & 95,35 & 96,16 & 93,57 & 94,73 \\
\hline & 72,5 & 100,00 & 89,66 & 93,14 & 95,95 & 95,89 & 96,95 & 94,33 & 95,02 \\
\hline & 75,0 & 100,00 & 89,43 & 93,11 & 96,52 & 96,51 & 97,83 & 95,18 & 95,36 \\
\hline & 77,5 & 100,00 & 89,21 & 93,07 & 97,23 & 97,23 & 98,84 & 96,17 & 95,76 \\
\hline & 80,0 & 100,00 & 88,99 & 93,03 & 98,16 & 98,11 & 100,04 & 97,36 & 96,24 \\
\hline & 82,5 & 100,00 & 88,79 & 92,99 & 99,42 & 99,23 & 101,52 & 98,84 & 96,84 \\
\hline & 85,0 & 100,00 & 88,60 & 92,95 & 101,27 & 100,74 & 103,46 & 100,83 & 97,64 \\
\hline & 87,5 & 100,00 & 88,45 & 92,91 & 104,33 & 102,96 & 106,26 & 103,77 & 98,77 \\
\hline & 90,0 & 100,00 & 88,35 & 92,86 & 110,79 & 106,81 & 111,04 & 108,98 & 100,54 \\
\hline
\end{tabular}


Para as duas espécies, a adição de $0,1 \%$ de espalhante permitiu reduzir as doses de glyphosate em aproximadamente $10 \%$, mantendo-se o mesmo nível de controle. Com a adição de $0,2 \%$ (do p.c. Aterbane), foi possível reduzir as doses de glyphosate em aproximadamente 1,5 e 7\%, para $B$. decumbens e $P$. maximum, respectivamente.

Considerando todos os demais tratamentos, com destaque para as duas maiores concentrações do espalhante, verificou-se a necessidade de elevar substancialmente as doses do herbicida para que fossem alcançadas as maiores porcentagens de controle, justamente as de maior interesse prático. A provável justificativa para este comportamento foi o escorrimento da calda de pulverização, visualmente detectável logo após a aplicação, nos tratamentos correspondentes às concentrações de 0,75 e 1,0\% (p.c.).

Nas Figuras 16 e 17, são plotados os desvios dos dados originais em relação às curvas gerais de controle, em função das tensões superficiais. Para simplificar a interpretação dos gráficos, foram calculados os desvios médios para 4 classes de tensão, apresentados na Tabela 7.

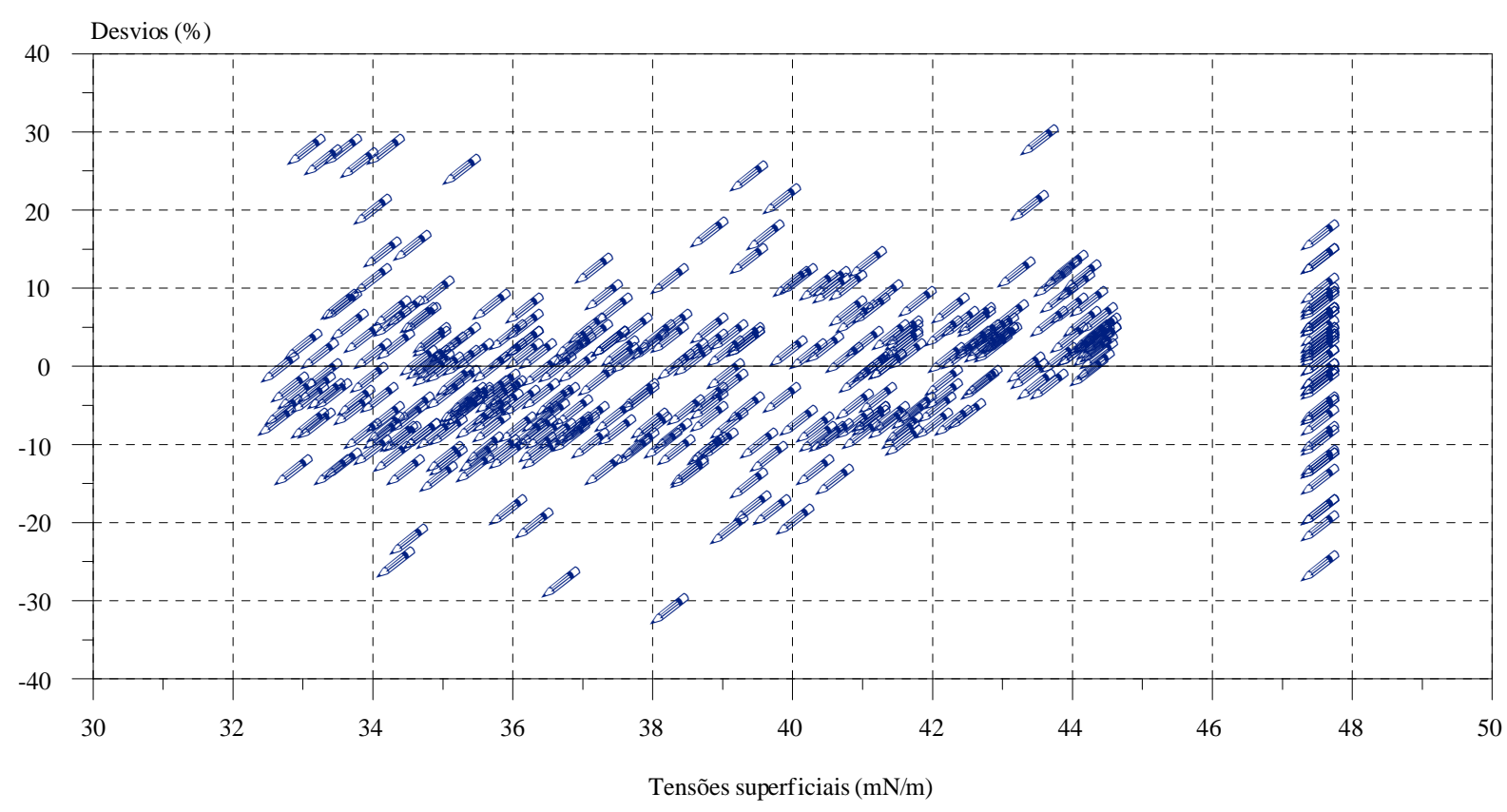

FIGURA 16. Desvios em relação à curva geral de controle, para Brachiaria decumbens, em função da tensão superficial $(\mathrm{mN} / \mathrm{m})$.

Embora seja grande a dispersão dos dados pode-se observar que quando a tensão superficial encontra-se entre 42,5 e $45 \mathrm{mN} / \mathrm{m}$, os desvios médios, para as duas espécies, foram positivos e próximos a 5\%, indicando aumentos desta magnitude nas porcentagens de controle. Há a necessidade de novos estudos para que estes resultados sejam comprovados, ou não. Se comprovados, as concentrações do(s) espalhante(s) poderiam ser ajustadas em função da tensão superficial que se deseja alcançar.
Quanto à metodologia utilizada, mostrouse adequada aos propósitos do trabalho, permitindo a obtenção de informações precisas e em grande número. Deve ser destacada a utilidade do pulverizador logarítmico, neste tipo de estudo. Como a variação das doses é contínua, há uma infinidade de condições disponíveis para avaliação. $\mathrm{O}$ pesquisador pode selecionar $a$ posteriori as dosagens que deseja considerar, ajustando a distância e a amplitude das mesmas à magnitude das diferenças entre os tratamentos. 


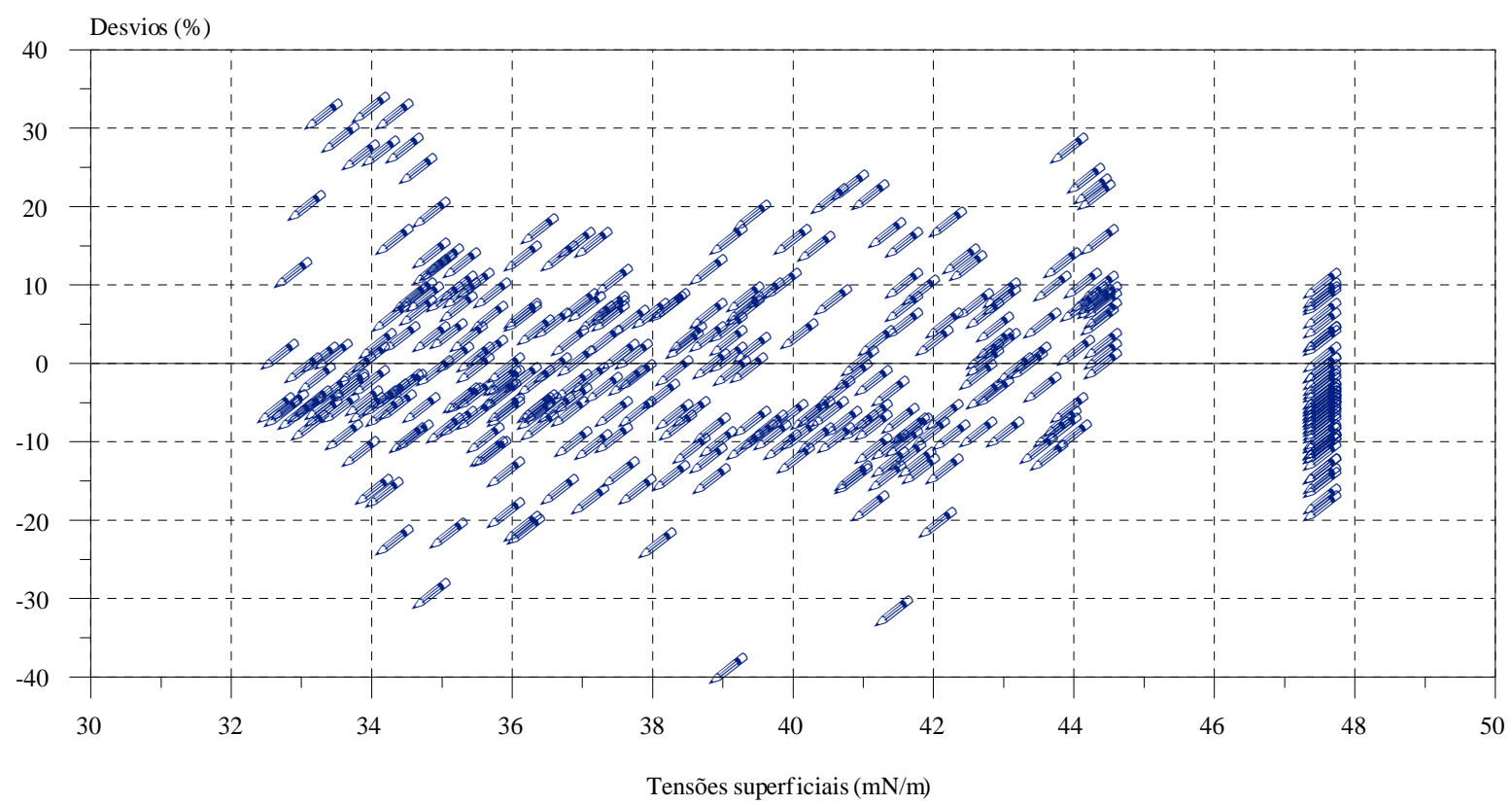

FIGURA 17. Desvios em relação à curva geral de controle, para Panicum maximum, em função da tensão superficial (mN/m).

TABELA 7. Desvios médios em relação às curvas gerais de controle, para distintas classes de tensão superficial (TS). Botucatu/SP, 1.995.

\begin{tabular}{ccc}
\hline Classes de Tensão & \multicolumn{2}{c}{ Desvios médios** } \\
\cline { 2 - 3 }$(\mathrm{mN} / \mathrm{m})^{*}$ & $-1,44$ & Panicum maximum \\
\hline $\mathrm{TS}<40$ & 0,17 & 0,47 \\
$40,0 \leq \mathrm{T}<42,5$ & 5,65 & $-1,72$ \\
$42,5 \leq \mathrm{T}<45,0$ & $-1,24$ & 4,69 \\
$\mathrm{~T}>45,0$ & & $-4,46$ \\
\hline
\end{tabular}

*mili Newtons / metro; **em relação às curvas gerais de controle e expressos em \%.

Em função do número e da amplitude das doses estudadas, foi possível avaliar melhor a interação herbicida x espalhante. Considerando, por exemplo, o Panicum maximum, ficou evidente que o efeito do espalhante depende muito da dose do herbicida. Para doses de até 3,5 1 p.c./ha, a eficiência mostrou-se crescente com o aumento da concentração do espalhante. Para doses superiores a esta, destacaram-se os tratamentos com 0,1 e $0,2 \%$ do espalhante. Com o uso de experimentos 
convencionais, que normalmente seriam conduzidos considerando as doses de 6 e $31 /$ ha, correspondentes à dose normal e metade da mesma, seria praticamente impossível avaliar e quantificar adequadamente esta interdependência de efeitos e alcançar o principal objetivo do trabalho que é o de estimar as possíveis reduções de dose do herbicida em função do uso do espalhante.

\section{LITERATURA CITADA}

CAMARGO,P. N., SILVA, O. Manual de adubação foliar. La Libreria e Herba Ltda., São Paulo, 1975. 278 p.

DURIGAN, J.C. Efeitos de adjuvantes na aplicação e eficácia dos herbicidas. Jaboticabal, FUNEP, 1993, 42 p.

FOLONI, L.L. Respostas da utilização de bicos de baixa vazão com glyphosate e sulfosate no controle do arroz vermelho, em aplicação de pré-plantio, em área de plantio direto de arroz (Oryza sativa L.) In: REUNIÃO DA CULTURA DO ARROZ IRRIGADO, 21, Porto Alegre, 1995. Anais... p.253.

MATUO, T., NAKAMURA, S.H., ALMEIDA, A.
Efeitos de alguns adjuvantes da pulverização nas propriedades físicas do líquido. Sum. Phytop., v. 15, p. 163-73, 1989.

MENDONÇA, C.G., MENDONÇA, C.G., VELINI, E.D., MARTINS, D. Avaliação dos efeitos de distintos espalhantes adesivos sobre a tenão superficial e o contato de glyphosate com folhas de Cyperus rotundus L. Botucatu, 1996, 41 p. (monografia).

SILVA, M.A.S. Efeitos de periodos sem chuva, dosagens e volumes de aplicação de glyphosate no controle de Brachiaria decumbens Stapf. Botucatu, 1996. 67 p. Dissertação (Mestrado em Agricultura) Faculdade de Ciências Agronômicas, Universidade Estadual Paulista.

VELINI, E.D., GAVLAK, R., RIBEIRO, O.C., ANTUNIASSI, U.R. Avaliação da tensão superficial de soluções do espalhante adesivo alquil-fenol-poliglicoléter, isolado ou em mistura com o herbicida glyphosate. In: CONGRESSO BRASILEIRO DE HERBICIDAS E PLANTAS DANINHAS, XIX, 1993. Londrina, Resumos ...Londrina: SBHED, 1993. p.264. 